\title{
Effect of human cytomegalovirus infection on the expression of Hoxb2 and Hoxb4 genes in the developmental process of cord blood erythroid progenitors
}

\author{
WEN-JUN LIU, MEI-XIAN HUANG, QU-LIAN GUO,JUN-HONG CHEN and HAN SHI \\ Department of Pediatrics, Hospital Affiliated to Luzhou Medical College, Luzhou, Sichuan 646000, P.R. China
}

Received June 29, 2011; Accepted August 22, 2011

DOI: $10.3892 / \mathrm{mmr} .2011 .576$

\begin{abstract}
The aim of the present study was to investigate the role of Hoxb2 and Hoxb4 gene expression induced by human cytomegalovirus (HCMV) and/or all-trans retinoic acid (ATRA) on the proliferation and committed differentiation process of human cord blood hematopoietic stem cells (HSCs) to colony-forming erythroid progenitor cells (CFU-Es) in vitro. Cord blood was collected from the fetal placenta umbilical vein in 12 cases and cultured using hematopoietic stem cell culture technique in vitro. The proliferation and differentiation of cord blood HSCs to CFU-Es were continuously disrupted with HCMV-AD169 and/or 6x10 ${ }^{-8} \mathrm{~mol} / \mathrm{l}$ of ATRA. Expression levels of the Hoxb2 and Hoxb4 genes in the blank, ATRA, HCMVAD169 and ATRA + HCMV treatment groups of CFU-Es were detected on day 3, 7 and 10 of culture by fluorescent quantitative reverse transcriptase-polymerase chain reaction method. Hoxb2 and Hoxb4 gene expression in each group began on day 3 , obviously increased on day 7 and reached a peak on day 10 . The expression levels of the Hoxb2 and Hoxb4 genes in the HCMV group were obviously down-regulated compared with the level in the blank group. However, expression levels of the Hoxb2 and Hoxb4 genes were significantly up-regulated in the HCMV + ATRA group compared with the HCMV group $(\mathrm{P}<0.05)$. Abnormal expression of the Hoxb2 and Hoxb4 genes induced by HCMV may play important roles in abnormal hematopoietic damage. They were also correlated with the process of erythroid hematopoiesis. ATRA $\left(6 \times 10^{-8} \mathrm{~mol} / \mathrm{l}\right)$ significantly up-regulated expression of the Hoxb2 and Hoxb4 genes in the normal erythroid progenitor cells and in those cells infected with HCMV as well.
\end{abstract}

Correspondence to: Dr Wen-Jun Liu, Department of Pediatrics, Affiliated Hospital to Luzhou Medical College, Luzhou, Sichuan 646000, P.R. China

E-mail:wenjunliucn@126.com

Key words: cytomegalovirus, erythroid progenitor cells, fluorescent quantitative reverse transcriptase polymerase-chain reaction, all-trans retinoic acid, Hoxb2, Hoxb4

\section{Introduction}

Human cytomegalovirus (HCMV) is one of the most prevalent infective factors among the population worldwide. HCMV together with toxoplasm, rubella virus, herpes simplex virus and treponema pallidum are regarded as five biological teratogenic factors. The incidence rates of HCMV infection have reached $80-90 \%$ among the Chinese (1), which is even higher among children. Numerous studies have shown that the hematopoietic system is one of the major organs suffering from HCMV infection. We found that HCMV directly damages hematopoietic progenitor cells and leads to abnormal expression of the homeobox gene (Hox) in infected cells (2-9). Recent studies have shown that the Hox gene is associated with the development of hematopoietic cells and directly affects the proliferation, differentiation and maturity of hematopoietic stem cells due to structural and functional alterations. Hoxb2 and Hoxb4 genes are considered to be the major regulatory factors in the proliferation and differentiation process of erythroid cells $(10,11)$. Meanwhile, the expression of the Hox genes can be regulated by all-trans retinoic acid (ATRA). In the present study, the role of the expression of the Hoxb2 and Hoxb4 genes was assessed in the proliferation and committed differentiation process of human cord blood hematopoietic stem cells to colony-forming erythroid progenitor cells (CFUEs), and the mechanism of cord blood CFU-E damage caused by HCMV infection was evaluated at the gene level.

\section{Materials and methods}

Placental cord blood of 12 full-term infants was obtained at the Obstetrics Department, Affiliated Hosptial of Luzhou Medical College. All of the new mothers were in good health with HBSAg (-). The indices of serum anti-HCMV-IgG and HCMV-IgM of samples detected by ELISA and HCMV-DNA assessed by PCR methods were negative. HCMV-AD 169 virus strain with a titer of $10^{9} \mathrm{pfu} / \mathrm{l}$ was from the Institute of Virology, Chinese Academy of Preventive Medicine. The titer used for infection was adjusted to $10^{8} \mathrm{pfu} / \mathrm{l}$ by dilution with DMEM/F12 culture medium.

Isolation of cord blood mononuclear cells and culture and the identification of CFU-Es. Cord blood mononuclear cells 
Table I. Culturing system of the colony-forming erythroid progenitor cells.

\begin{tabular}{lcccc}
\hline Culture composition & Blank & HCMV & ATRA & HCMV + ATRA \\
\hline Fetal bovine serum $(\%)$ & 30 & 30 & 30 & 30 \\
2-mercaptoethanol $\left(10^{-4}\right.$ mmol/l) & 5 & 5 & 5 & 5 \\
Cord blood mononuclear cells $\left(10^{8} / \mathrm{l}\right)$ & 3 & 3 & - & 3 \\
HCMV & - & + & + & + \\
ATRA $\left(6 \times 10^{-8} \mathrm{~mol} / \mathrm{l}\right)$ & - & + & + \\
DMEM/F12 & + & + & + \\
Erythropoietin $(10 \mathrm{IU} / \mathrm{ml})$ & + & + & +
\end{tabular}

HCMV, human cytomegalovirus; ATRA, all-trans retinoic acid.

Table II. Sequences of the RT-PCR primers.

\begin{tabular}{lll}
\hline Gene & \multicolumn{1}{c}{ Primer, forward } & \multicolumn{1}{c}{ Primer, reverse } \\
\hline Hoxb2 & 5'-AAGCGAGCCGAAGATGGG-3' & 5'-CAGTCCCAGGCCATCTGC-3' \\
Hoxb4 & 5'-GCAAAGAGCCCGTCGTCT-3' & 5'-GAAATTCCTTCTCCAGCT-3' \\
GAPDH & 5'-CCTCAAGATCATCAGCAAT-3' & 5'-CCATCCACAGTCTTCTGGGT-3'
\end{tabular}

Table III. TaqMan probe sequences.

\begin{tabular}{ll}
\hline Gene & TaqMan probe \\
\hline Hoxb2 & 5'-FAM-CGG AGA AGG AGA CGT GGC GGA-TAMRA-3' \\
Hoxb4 & 5'-FAM-CGT GAA CTT TGC GCA TCC AGG-TAMRA-3' \\
GAPDH & 5'-FAM-ACC ACA GTC CAT GCC ATC AC-TAMRA-3'
\end{tabular}

Table IV. Expression levels of Hoxb2 in the human cord blood colony-forming erythroid progenitor cells treated with HCMV and/ or ATRA at different time points (mean $\pm \mathrm{SD}, \mathrm{n}=12$ ).

\begin{tabular}{llcc}
\hline Group & Day 3 & Day 7 & Day 10 \\
\hline Blank & $0.666 \pm 0.043$ & $0.709 \pm 0.028^{\mathrm{a}}$ & $0.768 \pm 0.024^{\mathrm{a}, \mathrm{b}}$ \\
HCMV & $0.630 \pm 0.042^{\mathrm{c}, \mathrm{d}}$ & $0.669 \pm 0.035^{\mathrm{a}, \mathrm{c}, \mathrm{d}}$ & $0.719 \pm 0.046^{\mathrm{a}, \mathrm{b}, \mathrm{c}, \mathrm{d}}$ \\
ATRA + HCMV & $0.649 \pm 0.048^{\mathrm{c}}$ & $0.720 \pm 0.033^{\mathrm{a}, \mathrm{c}}$ & $0.828 \pm 0.048^{\mathrm{a}, \mathrm{b}, \mathrm{c}}$ \\
ATRA & $0.743 \pm 0.038^{\mathrm{c}, \mathrm{d}}$ & $0.806 \pm 0.048^{\mathrm{a}, \mathrm{c}, \mathrm{d}}$ & $0.934 \pm 0.052^{\mathrm{a}, \mathrm{b}, \mathrm{c}, \mathrm{d}}$ \\
F & $\mathrm{F}$ (group) $=120.211 ; \mathrm{F}($ time $)=76.725 ; \mathrm{F}$ (total $)=94.120$
\end{tabular}

$\mathrm{F} \quad \mathrm{F}($ group $)=120.211 ; \mathrm{F}($ time $)=76.725 ; \mathrm{F}($ total $)=94.120$

HCMV, human cytomegalovirus; ATRA, all-trans retinoic acid. ${ }^{\mathrm{P}}<0.05$ vs. day 3 ; ${ }^{\mathrm{b}} \mathrm{P}<0.05$ vs. day 7 ; ${ }^{\mathrm{P}}<0.05$ vs. blank group; ${ }^{\mathrm{d}} \mathrm{P}<0.05$ vs. ATRA + HCMV group.

were isolated according to a conventional isolation method. An optimizing method applied in our department was used for the CFU-E culture. It is convenient to extract total RNA at different time points by supplementing methylcellulose in culture medium (Table I).

Identification of erythroid progenitor cells. Benzidine was added to the culture medium on day 3, 7 and 10 for iden- tification of the erythroid progenitor cells. The morphology, size and color of the cells were observed using an inverted microscope.

RNA extraction. Total RNA was isolated from cells in the different groups on day 3, 7 and 10 of culture using TRIzol reagent according to the manufacturer's instructions, followed by detection using $10 \mathrm{~g} / \mathrm{l}$ agarose gel electrophoresis and pres- 
Table V. Expression of Hoxb4 in human cord blood colony-forming erythroid progenitor cells treated by HCMV and/or ATRA at different time points (mean $\pm \mathrm{SD}, \mathrm{n}=12$ ).

\begin{tabular}{llll}
\hline Group & Day 3 & Day 7 & Day 10 \\
\hline Blank & $0.702 \pm 0.039$ & $0.747 \pm 0.046^{\mathrm{a}}$ & $0.843 \pm 0.052^{\mathrm{a}, \mathrm{b}}$ \\
HCMV & $0.639 \pm 0.041^{\mathrm{c}, \mathrm{d}}$ & $0.701 \pm 0.045^{\mathrm{a}, \mathrm{c}, \mathrm{d}}$ & $0.758 \pm 0.046^{\mathrm{a}, \mathrm{b}, \mathrm{d}, \mathrm{d}}$ \\
ATRA + HCMV & $0.704 \pm 0.035^{\mathrm{c}}$ & $0.769 \pm 0.048^{\mathrm{a}, \mathrm{c}}$ & $0.872 \pm 0.047^{\mathrm{a}, \mathrm{b}, \mathrm{c}}$ \\
ATRA & $0.779 \pm 0.048^{\mathrm{c}, \mathrm{d}}$ & $0.889 \pm 0.048^{\mathrm{a}, \mathrm{c}, \mathrm{d}}$ & $1.058 \pm 0.033^{\mathrm{a}, \mathrm{b}, \mathrm{c}, \mathrm{d}}$ \\
F & $\mathrm{F}$ (group) $=146.666 ; \mathrm{F}($ time $)=106.665 ; \mathrm{F}($ total $)=122.665$
\end{tabular}

HCMV, human cytomegalovirus; ATRA, all-trans retinoic acid. ${ }^{\mathrm{a}} \mathrm{P}<0.05$ vs. day 3 ; ${ }^{\mathrm{b}} \mathrm{P}<0.05$ vs. day 7 ; ${ }^{\mathrm{c}} \mathrm{P}<0.05$ vs. blank group; ${ }^{\mathrm{d}} \mathrm{P}<0.05$ vs. ATRA + HCMV group.

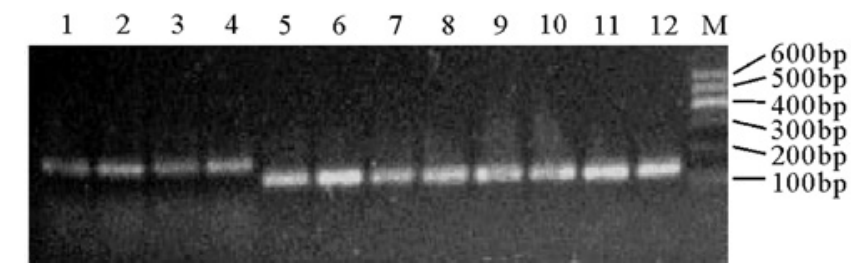

Figure 1. Comparisons of the expression levels of the Hoxb2 and Hoxb4 genes on day 3. Lanes, 1-4, Hoxb2 (198 bp); 5-8, Hoxb4 (138 bp); 9-12, GAPDH reference gene (141 bp); 1 and 5, blank group; 2 and 6, all-trans retinoic acid (ATRA) + human cytomegalovirus (HCMV) group; 3 and 7, HCMV group; 4 and 8 , ATRA group.

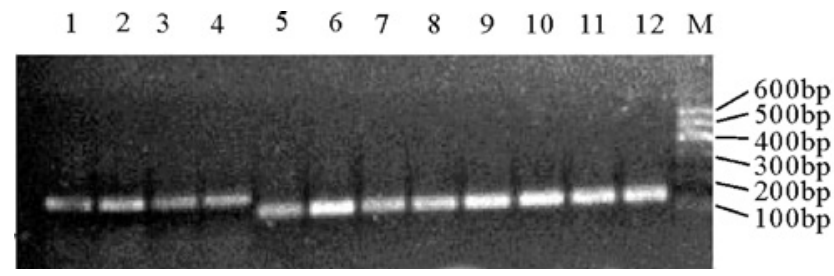

Figure 2. Comparisons of the expression levels of the Hoxb2 and Hoxb4 genes on day 7. Lanes, 1-4, Hoxb2 (198 bp); 5-8, Hoxb4 (138 bp); 9-12, GAPDH reference gene (141 bp); 1 and 5, blank group; 2 and 6, all-trans retinoic acid (ATRA) + human cytomegalovirus (HCMV) group; 3 and 7, HCMV group; 4 and 8, ATRA group.

ervation at $-85^{\circ} \mathrm{C}$ for real-time quantitative fluorescent-PCR assay (RQ-PCR).

Real-time fluorescent quantitative-PCR. The Hoxb2 and Hoxb4 genes were amplified using $5 \mu \mathrm{l}$ synthesized cDNA from total RNA as a template and designed DNA sequences as primers (Table II). PCR production was detected by agarose gel electrophoresis and preserved at $-20^{\circ} \mathrm{C}$. cDNA templates were 10 -fold serially diluted and served as standards with presumed original copy number $\left(10^{4}\right)$. A sample $(5 \mu \mathrm{l})$ from each standard was added to a $30-\mu 1$ reaction system including $3 \mu \mathrm{l} 10 \mathrm{X}$ buffer, $3 \mu \mathrm{l} \mathrm{MgCl}_{2}$ at $25 \mathrm{mmol} / 1,9 \mu \mathrm{dNTP}$ at $10 \mathrm{mmol} / 1,1 \mu \mathrm{dNTP}$ at $10 \mathrm{mmol} / 1,1 \mu \mathrm{l}$ upstream primers at $10 \mu \mathrm{mol} / 1,1 \mu \mathrm{l}$ downstream primers at $10 \mu \mathrm{mol} / 1,1 \mu \mathrm{l}$ TaqMan probes at $10 \mu \mathrm{mol} / 1$ (Table III), $0.3 \mu 1$ Taq DNA polymerase, $14.8 \mu \mathrm{l}$ DEPC- $\mathrm{H}_{2} \mathrm{O}$ and $5 \mu \mathrm{l} \mathrm{cDNA}$ template. The PCR reaction was performed using an FTC2000 fluorescent

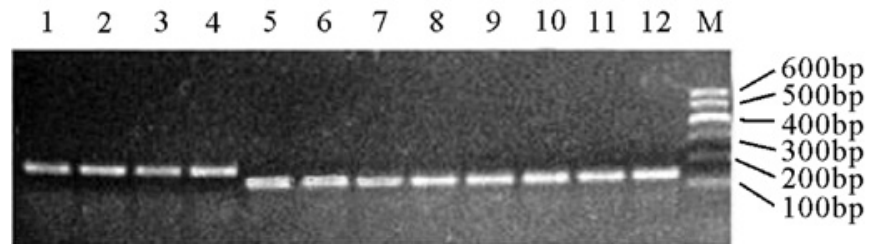

Figure 3. Comparisons of the expression levels of the Hoxb2 and Hoxb4 genes on day 10. Lanes 1-4, Hoxb2 (198 bp); 5-8, Hoxb4 (138 bp); 9-12, GAPDH reference gene (141 bp); 1 and 5, blank group; 2 and 6, all-trans retinoic acid (ATRA) + human cytomegalovirus (HCMV) group; 3 and 7, HCMV group; 4 and 8 , ATRA group.

quantitative PCR cycler. The conditions were as follows: an initial denaturation cycle at $95^{\circ} \mathrm{C}$ for $60 \mathrm{sec}$ and 45 cycles at $95^{\circ} \mathrm{C}$ for $10 \mathrm{sec}$, annealing at $55^{\circ} \mathrm{C}$ for $30 \mathrm{sec}$, and extension at $72^{\circ} \mathrm{C}$ for $1 \mathrm{~min}$. The specificity of the PCR amplification was checked by a melting curve program. The copy numbers of target genes were calculated with the obtained $\mathrm{Ct}$ values by using standard curves.

Erythroid progenitor cells were harvested on day 3, 7 and 10 for detecting the mRNA expression of Hoxb2 and Hoxb4 genes by RQ-PCR.

Statistical analysis. Data were calculated by a comparative threshold method using SPSS version 15.0. The fold change in expression was calculated for each sample using $2^{-\Delta \Delta C t}$, and the values for the expression levels of Hoxb2 and Hoxb4 were represented as means \pm SD. A pairwise comparison of mean values between groups (LSD method) was performed after detecting a significant difference by the Homogeneity test for variance and two-way analysis of variance. A P-value of $<0.05$ was considered statistically significant.

\section{Results}

RT-PCR amplification of Hoxb2, Hoxb4 and GAPDH genes. The sizes of the amplified bands were 198, 138 and $141 \mathrm{bp}$ which were consistent with the expected fragments of Hoxb2, Hoxb4 and GAPDH, respectively (Figs. 1-3).

Expression levels of Hoxb2 and Hoxb4. The result in Tables IV and $\mathrm{V}$ show that the expression levels of Hoxb2 and Hoxb4 in 
the ATRA group were significantly increased while they were decreased in the HCMV group compared to those of the blank group $(\mathrm{P}<0.05)$. There was no significant difference between the ATRA + HCMV and blank groups $(\mathrm{P}>0.05)$. Expression levels in the ATRA + HCMV group were significantly higher compared to those of the HCMV group $(\mathrm{P}<0.05)$.

The expression levels of Hoxb2 and Hoxb4 in each group were time-dependent and continued to increase on day 3, 7 and 10. Statistical differences were noted between the two groups in terms of the protein levels $(\mathrm{P}<0.05)$.

The results showed that both Hoxb2 and Hoxb4 were expressed in cord blood erythroid progenitor cells and were correlated with erythroid hematopoiesis; expression of Hoxb2 and Hoxb4 was visible on day 3, significantly increased by day 7 and reached the highest level by day 10 in the process of human hemopoietic stem cell proliferation and committed differentiation to erythroid progenitor cells. HCMV may lead to abnormal hematopoietic function through the down-regulation of Hoxb2 and Hoxb4 gene expression; $6 \times 10^{-8} \mathrm{~mol} / \mathrm{l}$ of ATRA up-regulated the expression of Hoxb2 and Hoxb4 in normal erythroid progenitor cells and those of cells infected by HCMV.

\section{Discussion}

HCMV infection is a common disease and a hazard to human health, particularly in children. The hematopoietic system is one of the major organs involved in HCMV infection and hematopoietic progenitor cells are the major potential sites for its occurrence. One of the mechanisms of hematopoietic suppression caused by HCMV comes from its inhibitory effect on hematopoietic progenitor cells (12). In this study, the expression of the Hoxb2 and Hoxb4 genes was detected during the process of proliferation and differentiation of human cord blood hemopoietic stem cells to erythroid progenitor cells caused by HCMV infection. The results indicated that HCMV markedly down-regulated the expression of Hoxb2 and Hoxb4, which exerted an effect on the proliferation and differentiation of erythroid progenitor cells.

The mechanism involved in the abnormal expression of the Hox genes caused by HCMV remains unclear. Presumably, the reasons may be as follows: HCMV infection often breaks several chromosome loci in which a common locus is $17 \mathrm{q} 21$ 22, whereas Hoxb2 and Hoxb4 are located on chromosome 17 (13); expression of Hox genes are regulated by ATRA, and HCMV-major immediate-early promoter (HCMV-MIEP) regulates the expression of the ATRA receptor which may influence the proliferation and differentiation of hematopoietic stem cells (14); HCMV-MIEP may have an effect on the expression of Hoxb genes due to expression of the HCMV gene induced by HCMV chromatin after infection $(15,16)$; the effects on HCMV infection and p38 MAPK showed a chronological feature which was also cell type-specific (17). In addition, Thrombopoietin (TPO) may up-regulate expression of Hoxb4 via p38 MAPK (18) resulting in abnormal erythroid hematopoietic function. Therefore, expression of Hoxb2 and Hoxb4 caused by HCMV infection may be associated with the MAPK signal transduction pathway.

Hoxb2 was only detected at the late stage of differentiation of erythroid cells. Hoxb2 expression is regulated by GATA-1 and interacts with the control region of the $\gamma$-globulin gene
(10). Díaz et al (19) found that p160 is a novel regulator of Prep1-Pbx1 transcriptional activity and inhibits Prep1dependent Hoxb2 expression in retinoic acid-treated NT2-D1 cells. Regulation of the differentiation of hematopoietic stem cells via the inhibition of Hoxb2 expression by p160 warrants further study. In addition, another study showed that ATRA up-regulated Hoxb6 expression (20) which was consistent with our findings. Hoxb4 protein activity was found to sustain a rather high level at the early stage of mature erythroid cells and granulopoietic cells which directly influenced the proliferation of progenitor cells at the late stage (11) and accelerated the differentiation of hematopoietic stem cells $(21,22)$. Hoxb4 was found to up-regulate transcription factor AP-1 and its subunits Jun-B and ra-1 that allow for the up-regulation of the expression of cyclin D1, reduction in the cell cycle and acceleration of hemopoiesis (23). Nuclear factor Y, thrombopoietin and AP-1 complex may participate in the transcription of Hoxb4 (24). Nuclear factor Y and thrombopoietin were found to up-regulate the expression of Hoxb4 via the PKA and p38 MAPK signaling pathway, respectively (25). In the present study, the Hoxb2 and Hoxb4 genes were expressed in cord blood erythroid progenitor cells in vitro, which suggests that there is a correlation between Hoxb2 and Hoxb4 genes and erythroid hematopoiesis.

ATRA induces proliferation and differentiation in a variety of cells (26). ATRA (8-10 mol/l) promotes the proliferation and reduces apoptosis of hematopoietic stem cells. In the present study, the result showed that ATRA up-regulated the expression of Hoxb2 in the process of hematopoietic stem cell proliferation and committed differentiation to erythroid progenitor cells compared to the blank group induced by $6 \times 10^{-8} \mathrm{~mol} / 1$ of ATRA.

ATRA was found to induce expression of the Hox genes mainly depending on its retinoic acid receptor (RAR) and the retinene receptor that are present in cell nuclei. ATRA and the nuclear receptor in a dimeric form directly integrates with the ATRA-specific response element, which causes activation or inhibition of gene transcription (27). Studies have indicated that ATRA induces the expression of the Hox genes. Genes in the $3^{\prime}$ region of Hox are the earliest to be activated and have a high sensitivity to ATRA, while the result is actually the pposite for those in the 5' region. Allelic mutation of Hox genes is positively correlated with the phenotype, and the degree of mutation is associated with the number of interference factors. For instance, ATRA at a low concentration can promote hematopoietic stem cell differentiation to erythroid cells while it can inhibit this process at a high concentration. ATRA was found to stimulate the differentiation of granulopoietic cells to terminal cells and influenced the differentiation of hematopoietic stem cells during the embryonic period of mammals (28). ATRA $(1 \mu \mathrm{mol} / \mathrm{l})$ was found to inhibit proliferation and differentiation of human hematopoietic stem cells in vitro (29). The inhibition rate of human leukemia cell strains such as HL-60 was $50 \%$ as induced by $3 \times 10^{-10}$ to $10^{-9} \mathrm{mmol} / \mathrm{l}$ of ATRA while the proliferation rate was increased to $150 \%$ after treatment with $3 \times 10^{-9}$ to $10^{-8} \mathrm{mmol} / \mathrm{l}$ of ATRA.

In the present study, $6 \times 10^{-8} \mathrm{~mol} / 1$ of ATRA was utilized based on previous cell toxicity experiments as well as pertinent literature. The results showed that ATRA at this concentration up-regulates expression of the Hoxb4 gene in normal hema- 
topoietic progenitor cells. Additional studies are underway to determine the relationship between the concentration of ATRA and the expression of the Hox6 gene and how to influence the proliferation and differentiation of hematopoietic cells through the change in the ATRA concentration.

In addition, main immediate early antigens (IEA) were found to increase the enhancer acitivity of interleukin $6(1,30)$ and ATRA was found to inhibit interleukin 6 via its receptors (31). Thus, it is presumable that the inhibitory effect of ATRA on interleukin 6 via ATRA receptors may relieve HCMV infection to some degree.

In the present study, our experiments were only confined to in vitro hematopoietic inhibition caused by HCMV infection and the effect of HCMV/ATRA on the expression of the Hoxb2 and Hoxb4 genes. Thus, further studies are required to evaluate how HCMV inhibits hematopoiesis, how HCMV/ATRA regulates the expression of the Hoxb2 and Hoxb4 genes in vivo and how they cause damage to the hematopoietic system.

\section{References}

1. Fang F: Views about the diagnosis, treatment and prevention of child's cytomegalovirus diseases. Int J Pediatrs 33: 143-145, 2006

2. Liu WJ, Liu B, Guo QL, et al: Inhibitory effect of ganciclovir on proliferation of cord blood hematopoietic progenitor cells after infection of human cytomegalovirus in vitro. J Clin Rehab Tissue Eng Res 12: 593-597, 2008 .

3. Zhan P, Liu B, Liu WJ, et al: Effect of human cytomegalovirus on proliferation of multipotential hematopoietic progenitors and intervention study in vitro. Chin J Mod Med 15: 182-185, 2005

4. Liu B, Liu WJ, Guo QL, et al: The effect of human cytomeglavirus on proliferation of megakaryocyte progenitor cells in vitro. J Appl Clin Pediatr 19: 39-41, 2004.

5. Shi H, Liu WJ, Chen JH, et al: Expressions of Hoxb4 and Hoxb6 genes on proliferation and differentiation of hematopoietic stem cell of human umbilical cord blood to colony forming unit-T lymphocyte infected by human cytomegalovirus in vitro. J Appl Clin Pediatr 24: 757-759, 2009.

6. Chen A, Chen HY and Liu WJ: Expression of HOXA9 homeobox gene in granulocyte differentiation infected with HCMV. Chongqing Med 39: 1942-1947, 2010.

7. Feng JQ, Liu WJ, Chen HY, et al: Effect of human cytomegalovirus infection on the expression of Hoxc4 and Hoxc6 genes in the proliferation of lymphocytic progenitor cells. Zhongguo Shi Yan Xue Ye Xue Za Zhi 17: 141-145, 2009.

8. Zou Y, Liu WJ, Zhai XS, et al: Research of the expression of HOXC4 gene in the differentiation and proliferation of the hematopoietic stem cell to lymphocytic progenitor cell. Chongqing Med 39: 1839-1841, 2010.

9. Chen JH, Liu WJ and Guo QL: Effect of human cytomegalovirus on the expression of Hoxa9 and Hoxa10 homeobox gene in the proliferation of granulocyte progenitor in vitro. Chinese J Pract Pedi 25: 595-598, 2010.

10. Vieille-Grosjean I and Huber P: Transcription factor GATA-1 regulates human HOXB2 gene expression in erythroid cells. J Biol Chem 270: 4544-4550, 1995.

11. DU CQ, Huang MX and Liu WJ: Effect of ATRA on the expression of genes Hoxb2 and Hoxb4 in cord blood erythroid progenitors. Zhongguo Shi Yan Xue Ye Xue Za Zhi 17: 1516-1521, 2009.
12. Liu WJ, Jin RM, Fu XD, et al: Effect of human cytomegalovirus on proliferation of hematopoietic progenitor cells of cord blood. Zhongguo Dang Dai Er Ke Za Zhi 8: 85-89, 2006.

13. Heise MT and White LJ: An attenuating mutation in $\mathrm{nsP1}$ of the Sindbis-group virus S.A.AR86 accelerates nonstructural protein processing and up-regulates viral 26S RNA synthesis. J Virol 77: 1149-1156, 2003.

14. Chen LY, Dai G, Wu GJ, et al: Influence of human cytomegalovirus infection on the expression of HOX genes in human embryo lung cells. Hunan Yi Ke Da Xue Xue Bao 25: 440-442, 2000.

15. Reeves MB: Chromatin-mediated regulation of cytomegalovirus gene expression. Virus Res 157: 134-143, 2011.

16. Sinclair J: Chromatin structure regulates human cytomegalovirus gene expression during latency, reactivation and lytic infection. Biochim Biophys Acta 1799: 286-295, 2010.

17. Yurochko AD and Huang ES: Human cytomegalovirus binding to human monocytes induces immunoregulatory gene expression. J Immunol 162: 4806-4816, 1999.

18. Kirito K, Fox N and Kaushansky K: Thrombopoietin stimulates Hoxb4 expression: an explanation for the favorable effects of TPO on hematopoietic stem cells. Blood 102: 3172-3178, 2003.

19. Díaz VM, Mori S, Longobardi E, et al: p160 Myb-binding protein interacts with Prep1 and inhibits its transcriptional activity. Mol Cell Biol 27: 7981-7990, 2007.

20. Chen HY, Liu WJ, Chen A, et al: Effect of all-trans retinic acid on expression of HOXB6 gene in human cord blood CFU-GM and CFU-E. Chin J Mod Med 18: 1506-1510, 2008.

21. Friel J, Schiedlmeier B, Geldmacher M and Ostertag W: Stromal cells selectively reduce the growth advantage of human committed $\mathrm{CD} 34^{+}$hematopoietic cells ectopically expressing HOXB4. Growth Factors 24: 97-105, 2006.

22. Bowles KM, Vallier L, Smith JR, Alexander MR and Pedersen RA: HOXB4 overexpression promotes hematopoietic development by human embryonic stem cells. Stem Cells 24: 1359-1369, 2006

23. Zhu J, Zhang Y, Joe GJ, et al: NF-Ya activates multiple hematopoietic stem cell (HSC) regulatory genes and promotes HSC self-renewal. Proc Natl Acad Sci USA 102: 11728-11733, 2005.

24. Beslu N, Krosl J, Laurin M, et al: Molecular interactions involved in HOXB4-induced activation of HSC self-renewal. Blood 104: 2307-2314, 2004.

25. Miyake N, Brun AC, Magnusson M, et al: HOXB4-induced selfrenewal of hematopoietic stem cells is significantly enhanced by p21 deficiency. Stem Cells 24: 653-661, 2006.

26. Niu CS, Li MW, Ni YF, et al: Effect of all-trans retinoic acid on the proliferation and differentiation of brain tumor stem cells. J Exp Clin Cancer Res 29: 113, 2010.

27. Bel-Vialar S, Itasaki N and Krumlauf R: Initiating Hox gene expression: in the early chick neural tube differential sensitivity to FGF and RA signaling subdivides the Hoxb genes in two distinct groups. Development 129: 5103-5115, 2002.

28. Evans T: Regulation of hematopoiesis by retinoid signaling. Exp Hematol 33: 1055-1061, 2005.

29. Sammons J, Ahmed N, Khokher MA and Hassan HT: Mechanisms mediating the inhibitory effect of all-trans retinoic acid on primitive hematopoietic stem cells in human long-term bone marrow culture. Stem Cells 18: 214-219, 2000.

30. Botto S, Streblow DN, DeFilippis V, et al: IL-6 in human cytomegalovirus secretome promotes angiogenesis and survival of endothelial cells through the stimulation of survivin. Blood 117: 352-361, 2011.

31. Kirchmeyer M, Koufany M, Sebillaud S, et al: All-trans retinoic acid suppresses interleukin-6 expression in interleukin-1-stimulated synovial fibroblasts by inhibition of ERK1/2 pathway independently of RAR activation. Arthritis Res Ther 10: R141, 2008 . 